\title{
Anti-CD38-targeted IgG4-attenuated IFNa TAK-573
}

National Cancer Institute

\section{Source}

National Cancer Institute. Anti-CD38-targeted Ig G4-attenuated IFNa TAK-573. NCI

Thesaurus. Code C140427.

A proprietary preparation composed of an immunog lobulin G4 (IgG4) directed against the cell surface glycoprotein CD-38 (CD38) that is fused to an attenuated form of human interferon alpha (IFN alpha; IFNa), with potential immunomodulating and antineoplastic activities. Upon administration, the IgG4 moiety of the anti-CD38-targeted IgG4attenuated IFNa TAK-573 specifically targets and binds to CD38 on CD38-positive tumor cells. In turn, the IFNa moiety binds to cell-surface IFN receptors, and activates IFNmediated signal transduction pathways, which results in the transcription and translation of genes whose products may cause antiproliferative effects in CD38-positive tumor cells. CD38, a type II transmembrane glycoprotein, is present on various immune cells and hematologic malignancies, and its expression has been correlated with poor prognosis. 